\title{
Cryopreservation of lumpfish Cyclopterus lumpus (Linnaeus, 1758) milt
}

Gunnvør Norðberg, Asa Johannesen, Regin Arge

This study has established a successful protocol to cryopreserve lumpfish Cyclopterus lumpus (Linnaeus, 1758) milt. Three cryosolutions were tested based on Mounib's medium; the original medium including reduced I-glutathione (GSH), the basic sucrose and potassium bicarbonate medium without GSH, or with hen's egg yolk (EY). Dimethyl sulphoxide (DMSO) was used as the cryoprotectant along with all three diluents in a 1 to 2 dilution. Cryopreservation was performed with the mentioned cryosolutions at two freezing rates. Motility percentages of spermatozoa were evaluated using ImageJ with a computer assisted sperm analyzer (CASA) plug-in. Findings revealed that spermatozoa cryopreserved in Mounib's medium without GSH had a post-thaw motility score of 6.4 percentage points ( $\mathrm{pp}$ ) higher than those in the original Mounib's medium, and an addition of EY to the modified Mounib's medium lowered the post-thaw motility score by $19.3 \mathrm{pp}$. The difference in motility between both freezing rates was $13.0 \mathrm{pp}$, and samples cryopreserved on a $4.8 \mathrm{~cm}$ high tray resulted in a better post-thaw motility score. On average, cryopreserved milt had a $24.1 \mathrm{pp}$ lower post-thaw motility score than fresh milt. There was no significant difference in fertilisation success between cryopreserved and fresh milt. Cryopreservation of lumpfish milt has, to our knowledge, never been successfully carried out before. The established protocol will be a main contributing factor in a stable production of lumpfish juveniles in future. 
2 Gunnvør Norðberg, Asa Johannesen \& Regin Arge

3 Fiskaaling, Aquacultural Research Station of the Faroes, Við Áir, 430, Hvalvík, Faroe Islands. 4

5 Correspondence: G Norðberg, Fiskaaling, Við Áir, 430, Hvalvík, Faroe Islands. Phone: +298

6 774766. E-mail: gunnvorj@fiskaaling.fo

7 
1. Introduction

13 Cryopreservation is an effective method for long-term storage of viable spermatozoa in fish 14 (Blaxter, 1953). This technique offers several benefits including artificial fertilisation, which allows for efficient use of milt. This is especially useful in species from which milt samples are difficult to obtain (Ohta \& Izawa, 1996), or when limited volumes can be stripped (Clearwater \& Crim, 1995). Other advantages of the technique include the option to preserve declining stocks (Tian et al., 2008) and to retain genetic variability in broodstocks (Suquet et al., 2000).

Milt cryopreservation has been well established for some freshwater fish species belonging to families of salmonids (Billard, 1992), cyprinids (Billard et al., 1995) and siluroids (Legendre, Linhart \& Billard, 1996). Cryopreservation efforts for marine fish species were ongoing already in the 80's (Bolla, Holmefjord \& Refstie, 1987), and (several) successful cryopreservation protocols have been defined (Suquet et al., 2000), for e.g. Atlantic haddock (Melanogrammus aeglefinus) (Rideout, Trippel \& Litvak, 2004), Olive flounder (Paralichthys olivaceus) (Zhang et al., 2003), Brazillian flounder (Paralichthys brasiliensis) (Lanes et al., 2008), and Atlantic halibut (Hippoglossus hippoglossus) (Ding et al., 2011). However, it is a challenging task to determine an optimal protocol for cryopreservation of milt for any particular fish species as diluent and cryoprotectant selection, dilution ratio, as well as freezing and thawing rates are parameters that interact with one another, and have all been found to vary greatly between species (Suquet et al., 2000; Rideout, Trippel \& Litvak, 2004).

Recent research has shown that lumpfish (Cyclopterus lumpus), an epibenthic-pelagic fish species naturally found in the North Atlantic Ocean, is an effective cleaner fish in combating infestation with sea lice (Lepeophtheirus salmonis and Caligus elongats) among farmed salmon

36 (Imsland et al., 2014), which is a growing problem in that industry (Costello, 2009a).

37 Commercial production of lumpfish juveniles is ongoing in Norway (Willumsen, 2001; Schaer \& 
38 Vestvik, 2012), and on the Faroe Islands our aim is to establish a year-round production of

39 lumpfish juveniles.

41 The lumpfish breeding season is considered to range from March to August (Johannesson 2006, 42 Kennedy et al., 2014), but in Faroese waters, mature lumpfish have been caught as late as in 43 November (own observation). During the breeding season, brood fish are obtained along the 44 coast lines, and are primarily captured by local fishing vessels using gillnets as the fish travel 45 from deep waters towards the shore for spawning (Holst, 1993; Muus, 1999). Males specifically, are found around the shores during the breeding season as they prepare their territory and wait for females to arrive, so spawning can take place (Goulet, Green \& Shears, 1986; Kennedy et al., 2014). Females lay their eggs in a nest site and then leave the spawning grounds for the males to stay and protect their offspring from predators (Muus, 1999; Kennedy et al., 2014). It has been reported that lumpfish males have a breeding period that lasts for 6 - 10 weeks (Davenport, 1985).

Reddish colouration is an indication that males have reached sexual maturity (Kells \& Carpenter, 2011). Our observation is however, that this is not always a guarantee that stripping is successful. Additionally, stripping most often results in small volumes of milt: in our trials volume ranged from 0.08 to $3.2 \mathrm{ml}$. This is a limiting factor when a large number of eggs from females are to be fertilized at the same time. Delaying stripping of females is unadvisable as eggs may become overripe or the female may release roe before artificial fertilisation can be carried out (e.g. at night), resulting in unfertilised roe (own observation). Cryopreservation of lumpfish milt could solve the issues mentioned above and ensure a year-round supply of male gametes for a sustainable juvenile production. Additionally, storing of milt from individuals with desirable genetic qualities may be important if breeding programmes are to be initiated for this species.

In a pilot study (supplementary data), we tested three cryosolutions (see supplementary table 1) previously found successful in the cryopreservation of milt from other marine fish species, including Atlantic haddock (Melanogrammus aeglefinus) and Atlantic cod (Gadus morhua)

67 (Rideout, Trippel \& Litvak, 2004), Olive flounder (Paralichthys olivaceus) (Zhang et al., 2003) 
69 three solutions, only spermatozoa cryopreserved in potassium bicarbonate and sucrose; the 70 modified Mounib's medium with 10\% DMSO (Dimethyl sulfoxide), as used by Ding et al. 71 (2011), resulted in motile spermatozoa post cryopreservation (see supplementary table 2). The 72 original Mounib's medium also includes 6.5mM reduced L-Glutathione (GSH) (Mounib, 1978), 73 which is known to prevent free radicals from oxidising the lipid bilayer in the cell membrane, 74 and thus prevents cell degradation. The role of sucrose in the medium is to stabilise the liposomal membrane of spermatozoa during cryopreservation (Quinn, 1985; Gwo, 2000).

Freezing rate has an effect on motility post-cryopreservation (Suquet et al., 2000). The height of the tray used in the cryopreservation process has a great effect on the rate. Rideout et al. (2004) found that a $3 \mathrm{~cm}$ high tray resulted in samples reaching $-90^{\circ} \mathrm{C}$ in 90 seconds whereas it took 12 minutes on a tray $5.5 \mathrm{~cm}$ high. They also found better survival in the spermatozoa when the freezing rate was slow. In accordance with this, our pilot study indicated better motility post cryopreservation when samples were cryopreserved on a $4.8 \mathrm{~cm}$ tray compared to a $2.5 \mathrm{~cm}$ tray (supplementary table 2).

Thawing temperature may also affect post-cryopreservation motility. For marine fish species, applied thawing temperatures typically vary between 10 and $40^{\circ} \mathrm{C}$ (Suquet et al., 2000), these are lower than temperatures used for milt samples from freshwater fish species, which vary between 30 and $80^{\circ} \mathrm{C}$ (Suquet et al., 2000). These findings correspond well to our pilot study where two thawing rates were tested; $37^{\circ} \mathrm{C}$ and $50^{\circ} \mathrm{C}$ and results showed clearly that lumpfish milt thawed in $37^{\circ} \mathrm{C}$ resulted in higher motility scores (supplementary table 2).

Our pilot study was unfortunately only based on milt samples from one lumpfish (stripped in 2012), so there were no replicates to base any firm conclusions on. Additionally, we did not have optimal equipment (cryo vials instead of straws) and were unable to carry out computer assisted sperm analysis (CASA).

Based on pilot study findings detailed above, we tested the efficacy of cryopreserving lumpfish milt (stripped in 2014) in three different diluents, all being variations based on Mounib's medium (100 millimolar $(\mathrm{mM})$ potassium bicarbonate $\left(\mathrm{KHCO}_{3}\right)$, and $125 \mathrm{~mm}$ sucrose $)$ as earlier 
100 findings indicated its success. We also tested the effect of two different freezing tray heights (4.8 101 and $6.4 \mathrm{~cm}$ ). Motility performances of fresh and cryopreserved spermatozoa were analysed using

102 a modern CASA system. Fertility post-cryopreservation was compared to the fertility of fresh

103 milt.

104

105

106

2. Materials \& Methods

107

108

\subsection{Experimental design}

109

Stripped milt from seven lumpfish males (weight: mean \pm SD; $459.53 \pm 348.10 \mathrm{~g}$, and length:

110

$22.44 \pm 5.21 \mathrm{~cm}$ ) was used in this experiment (some males were stripped more than once, so

$111 \mathrm{n}=16$ samples). Stripping volume ranged from 0.3 to $2.7 \mathrm{ml}$ per sample $(0.97 \pm 0.73)$

112 (supplementary table 3$)$. Motility percentage, $\mathrm{pH}(6.55 \pm 0.21)$, osmolality $(0.463 \pm 0.06$

$\left.113 \mathrm{mOsmol} \mathrm{kg}{ }^{-1}\right)$, and milt concentration $\left(31.44 \times 10^{9} \pm 8.35 \times 10^{9}\right.$ cells ml-1) were measured after

114 stripping each male. In the cryopreservation experiment, milt samples $(n=16)$ from seven fish

115 were cryopreserved in triplicates in the following diluents: 1) Mounib's medium without GSH

116 "Mounib no GSH", as in Ding et al. (2011), 2) Mounib's original medium (Mounib, 1978)

117 "Mounib", and 3) Mounib's medium as in "Mounib no GSH" but with added hen's egg yolk

118 (EY), which is a non-penetrating cryoprotectant that is commonly used in cryopreservation

119 (Jamieson, 1991) "Mounib plus EY". The cryoprotectant DMSO (10\%) was used with all three

120 diluents (table 1). Additionally, we test two tray heights: 1) the previously successful $4.8 \mathrm{~cm}$ tray

121 and, 2) a higher tray of $6.4 \mathrm{~cm}$ to ascertain whether an even slower freezing rate may further

122 increase motility. All milt samples were tested at two freezing rates except "Mounib", which was

123 only tested at one of these (tray height: $4.8 \mathrm{~cm}$ ) due to insufficient volumes of milt. For every

124 milt sample used in the cryopreservation experiment, a matching sample of fresh milt (obtained

125 from the same stripping) served as a control.

126

127

128

129

130

131

132

133

134 
135 Table 1 The chemical composition of the three cryosolutions tested in this experiment. All are based on Mounib's 136 basic medium with and without reduced l-glutathione and hen's egg yolk. Mounib no GSH and Mounib plus EY

137 were tested on two freezing trays (height 4.8 and $6.4 \mathrm{~cm}$ ), and Mounib was only tested on one tray (height $4.8 \mathrm{~cm}$ ).

138 The concentration in every sample was: milt to diluent $(1: 2)$ and $10 \%$ of the diluent volume was DMSO.

139

\begin{tabular}{l|l|l|l} 
Cryosolution: & Diluent: & Dilution: & Cryoprotectant \\
\hline Mounib & $\begin{array}{l}100 \mathrm{mM} \text { KHCO3, 125 mM Sucrose and } \\
6.5 \mathrm{mM} \text { L-Gluthatione (reduced) }\end{array}$ & $1: 2$ & $10 \%$ DMSO \\
\hline Mounib no GSH & $100 \mathrm{mM} \mathrm{KHCO3}$ and $125 \mathrm{mM}$ Sucrose & $1: 2$ & $10 \% \mathrm{DMSO}$ \\
\hline Mounib plus EY & $\begin{array}{l}100 \mathrm{mM} \text { KHCO3, 125 mM Sucrose and } \\
10 \% \text { hen egg yolk }\end{array}$ & $1: 2$ & $10 \%$ DMSO \\
\hline
\end{tabular}

\subsection{Gamete collection}

144 The majority of milt samples were obtained from fish produced from wild broodstock at Nesvík Marine Centre, Faroe Islands in 2013 ( $\mathrm{n}=12$ samples from five fish). Other samples were obtained from wild fish captured near the shore by divers 8-10 days prior to this experiment $(\mathrm{n}=$ 4 samples from two fish) (supplementary table 3). Fish were held in 3 metre diameter cylindrical tanks, water depth $1 \mathrm{~m}$ with flow through filtered and UV treated sea water (35\%). Fish were fed ad lib with $3 \mathrm{~mm}$ standard commercial fish feed, Atlantic salmon type: "Margæti" from Havsbrún, Faroe Islands. The feed contained $48 \%$ and $27 \%$ crude protein and fat respectively.

Males with a reddish appearance were placed in a tank along with females (one male/three

153 females) at ambient temperature $\left(9-10^{\circ} \mathrm{C}\right)$ for a few days prior to stripping in order to enhance gamete production (Klokseth \& Øiestad, 1999). A pre-stripping check was done by light pressure on the sides and abdomen of the males. If milt was released, fish were placed in a 20

156 litre container with sea water along with $20 \mathrm{ml}$ of Benzocaine (anaesthetic). Once fish were unconscious, the milt was collected into $5 \mathrm{ml}$ syringes, and placed on ice immediately. The fish were placed back into the tank with continually flowing sea water to recover. 
160 Eggs were obtained from wild females $(n=10)$ captured 8-10 days prior to our trials near Faroese 161 coastlines by local fishing vessels. Females with large bulging abdomens were easily identified

162 as carrying roe and swelling around the urogenital opening signalled imminent spawning. Before

163 stripping began, females were anaesthetized in same procedures as with the males mentioned 164 earlier. Eggs were stripped by placing 1-2 fingers into the urogenital opening to release the roe 165 and applying mild pressure to the abdomen, allowing the roe to drain into cleaned measuring 166 containers. The amount of stripped eggs ranged from $100 \mathrm{ml}$ to $400 \mathrm{ml}$ per fish. Stripped eggs 167 were immediately stored at $4^{\circ} \mathrm{C}$ until the fertilisation procedure was initiated, which was usually 168 within an hour.

169

170 Spermatozoa were counted under a microscope (Leica DM1000 led) using a hemocytometer 171 (thoma $0.1 \mathrm{~mm}$ ) using standard counting protocols: milt was diluted 1 to 1000 in a non activating 172 medium (NAM) previously used in Fauvel et al. (1998) prior to counting. $10 \mu$ of the dilution 173 was loaded into both counting chambers of the hemocytometer and allowed to settle for 10

174 minutes before counting the spermatozoa. Cells were counted in five squares each in two 175 chambers on the thoma cell counting chamber (not counting cells on the bottom and right edges) 176 and multiplied up to a cell count per ml. The osmolality of milt was measured using a Gonotec 177 Osmomat 030-D cryoscopic osmometer. The $\mathrm{pH}$ value of stripped milt was measured using a 178 PHM 62 standard $\mathrm{pH}$ meter.

\subsection{Motility measurements}

182 Triplicates of fresh milt samples were examined within 30 minutes after stripping. The milt was 183 diluted 1 to 200 in an activating medium (AM) made of 50\% filtered sea water (SW), and 50\% 184 bovine serum albumin (BSA) (VWR, Bie \& Berntsen, Denmark), prepared in distilled water (10 $185 \mathrm{mg} / \mathrm{ml}$ ) beforehand, to avoid the cells from sticking to the microscope slide. Immediately after 186 milt was added to the AM, the dilution was cautiously mixed with the pipette tip to distribute the 187 cells evenly, and then $6 \mu 1$ of the dilution was quickly transferred into one chamber of a Leja 2 188 chamber CASA microscope slide (SC-20-01-02-B) (Leja Products B.V. ). 
190 A two-step dilution procedure is often performed for measuring motility in milt (Dreanno et al.,

191 1997; Fauvel et al., 1999; Groison et al., 2010). This procedure involves first diluting milt in

192 NAM, an isotonic medium similar to the chemical composition of milt (Fauvel et al., 1998), in

193 order to keep spermatozoa quiescent. Subsequently, the milt dilution is transferred to a

194 microscope slide, where an activating agent (usually sea water) is added before monitoring the

195 spermatozoa. In our trials, this procedure resulted in an uneven distribution of spermatozoa when

196 the AM was added to the milt dilution within the chamber of the microscope slide. As lumpfish

197 spermatozoa may be motile up to several minutes (unpublished data), we chose to do a one-step

198 procedure and diluted all samples in the AM directly, which allowed us to get an even

199 distribution of cells for observation and recording video for the CASA system.

201 All samples were observed with phase contrast (PH2) under a Leica DM1000 led microscope

202 (object lens: 20x). A digital camera (Leica DFC 295) was attached to the microscope and

203 coupled to a computer, and with the included Leica application suit (LAS) software, a clear live

204 video feed of spermatozoa was obtained. Settings on the LAS software were adjusted to: $44.5 \mathrm{~ms}$

205 exposure, $1.4 \mathrm{x}$ gain and gamma 1.34, and image set to greyscale. Recording was achieved using

206 a Blueberry software (BB flashback Pro 4) player. Two minutes of each sample was recorded,

207 and the first 20 seconds of each movie were always excluded to avoid measurements of

208 spermatozoa moving due to flow and avoiding the lag period caused by mixing milt and AM,

209 and loading into the chamber of the slide. A total of 46 video frames were extracted from each

210 video and saved as AVI files. Image J (http://rsb.info.nih.gov/ij) (Rasband) open source

211 software, including a CASA plug-in that allows measuring the motility percentage of fish milt

212 (Wilson-Leedy \& Ingermann, 2007), was used for video analysis. To get accurate measurements

213 of motility percentage of lumpfish spermatozoa using the CASA plug-in in ImageJ, the image of

214 the imported AVI file threshold was adjusted to 57. In the CASA plug-in sperm tracker fields we

215 only adjusted a few settings to get accurate measurements, these included, the maximum sperm

216 size to 99 pixels, the minimum track length to 10 frames, the maximum sperm velocity between

217 frames to 50 pixels, and the frame rate to 10 frames per seconds (the video was recorded at

218 10fps).

219

220

\subsection{Cryopreservation and thawing.}


221 "Mounib" and "Mounib no GSH" diluents were prepared within a week before the 222 cryopreservation experiments, and stored at $4{ }^{\circ} \mathrm{C}$ along with hen's egg yolk. DMSO was stored 223 at room temperature. Milt samples in syringes were stored on ice not more than an hour before 224 the cryopreservation set-up was prepared. The cryopreservation set-up was prepared on ice; first 225 by adding diluent stock into cooled eppendorf tubes, thereafter DMSO. In cryosolution "Mounib 226 plus EY", egg yolk was added after the diluent, then the cryoprotectant. Finally, milt was added 227 to all tubes, and ingredients cautiously mixed by aspiration with a pipette, samples were allowed 228 to stand for a 10 minute equilibration time. All samples were cryopreserved in $250 \mu 1$ cryo229 straws (Cryo Bio System). Samples were drawn into the straws manually and sealed. They were 230 then attached on to the top of a floating tray that was either $4.8 \mathrm{~cm}$ in height, or $6.4 \mathrm{~cm}$ in height, 231 representing two freezing rates. Floating trays were placed within a Styrofoam box (inside 232 dimensions $\mathrm{H} \times \mathrm{L} \times \mathrm{W}=21 \mathrm{~cm} \times 35.5 \mathrm{~cm} \times 23 \mathrm{~cm})$ filled with liquid nitrogen $\left(-196^{\circ} \mathrm{C}\right)$ with an 233 approximate depth of $10 \mathrm{~cm}$ to allow straws to cool in the nitrogen gas layer for 10 minutes.

234 Thereafter, the trays were turned over and samples plunged directly into the liquid nitrogen and 235 left for at least 15 minutes before the thawing process was initiated. Straws were taken directly 236 from liquid nitrogen into a water bath at $37^{\circ} \mathrm{C}$ for a duration of 7 seconds to be thawed. The 237 ends of straws were cut off with scissors to allow the samples to drain into fresh cooled 238 eppendorf tubes. The examination of the cryopreserved milt was done in the same way as with 239 fresh milt samples, only difference being that cryopreserved samples, having already been 240 diluted in cryosolution, were diluted only 1 to 30 in the AM.

\subsection{Fertilization}

243 Lumpfish eggs become sticky and attach to each other on contact with sea water and form dense 244 lumps within a few minutes (Davenport, 1985). This property can make it difficult to obtain 245 good estimates of fertilisation success as visually inspecting roe on the inside of such lumps is impractical. Ballan Wrasse (Labrus bergylta) roe have a similar biochemical reaction when exposed to sea water, but mixing their roe with subtilisin, an enzyme also referred to as 'alcalase', along with Ringer's solution removes the egg stickiness and allows eggs to remain unattached (Lein et al. 2013). This method was tested in our own laboratory using lumpfish eggs with successful results (unpublished data) and was therefore incorporated into the fertilization procedure of this study. Before fertilization was initiated, the Ringer's solution found in Young 
252 (1933) was combined with 10\% Alcalase ${ }^{\circledR} 2.4$ L FG (Novozymes A/S). Each sample (20 ml; 253 about 2.300 eggs) was fertilised with milt at an approximately 1:30.000 egg to motile 254 spermatozoa ratio. After adding the milt sample to the eggs, approximately $10 \mathrm{ml}$ of sea water 255 was stirred in to activate the spermatozoa. The compounds were mixed by gently stirring for at 256 least $30 \mathrm{sec}$, and then allowed to stand for 2 minutes before $10 \mathrm{ml}$ of the Ringer's + alcalase 257 solution was added, and again gently stirred into to the sample for a few seconds to obtain an 258 even distribution. The mixture was allowed to stand for $5 \mathrm{~min}$ before being poured into a fresh 259 petri-dish containing SW (35\%), and gently stirred for a few seconds to dissolve the "glue" away 260 from the eggs. Fertilized eggs were then placed in round incubators (15 L) with eight 261 compartments separated by netting ( $1 \mathrm{~mm}$ mesh size) Water flow was set to $9 \mathrm{~L} \cdot \mathrm{min}^{-1}$ to allow 262 enough water change in all compartments. Water temperature was measured daily and ranged 263 between $11.1-11.3^{\circ} \mathrm{C}$. After 78.4 - 89.7 day degrees (dd), eggs were inspected under a 264 dissection microscope to ascertain fertilisation. Approximately 50-200 eggs were inspected in 265 each sample.

\subsection{Statistical analysis}

Analysis was carried out using R version 3.0.3 (R Core Team 2014) and Excel (MS Office). While motility and fertilisation data are measured in percentages, the residuals in the chosen linear mixed effects models were sufficiently normal (Shapiro-Wilks tests for normality: Effect of cryopreservation on motility; $\mathrm{W}=0.98, \mathrm{P}=0.41$, Effect of tray height and diluent type on motility; $\mathrm{W}=0.97, \mathrm{P}=0.36$, Effect of cryopreservation on fertility; $\mathrm{W}=0.96, \mathrm{P}=0.34$ ), so using generalized linear models or transforming the data was not justified in this case.

Effect of cryopreservation and the effects of diluent type and tray height on motility were analysed using similar models. In both cases, a linear mixed effects model, "lmer" in the R package lme4 (Bates et al., 2014) was used with the aforementioned dependent and independent variables as well as "batch" as a random effect. Batch refers to an individual stripping of milt and any one male may produce several batches of milt. We chose "batch" as the random effect because males did not differ significantly in motility scores (Anova; $\mathrm{F}_{6,9}=2.06, \mathrm{P}=0.16$ ), which can be explained by high within-male variation in motility (supplementary fig. 1). P values were 
283 Weisberg, 2011). Effect of cryopreservation of milt on fertilisation success was analysed using a 284 simple linear model.

285

Differences between treatments are expressed in percentage points $(\mathrm{pp})$ and means are provided with Standard Deviations.

\subsection{Ethical statement}

As there is no animal experimentation legislation on the Faroe Islands, the local "animal protection act" was adhered to (Vinnumálarádið, 1990) throughout this study. A fish veterinarian advised on best practice in relation to stripping to ensure no undue suffering caused by the procedure. Our impact on wild populations was limited, as we used predominately captive bred 294 fish, which were bred for the purpose of producing a domestic lumpfish stock. There were no 295 fish mortalities caused by our study and effort was put into providing optimal care and welfare 296 for all fish involved.

297

298

3. Results

299

Cryopreserved milt had a 24.1 pp lower motility than fresh milt (type II Wald test; Chi squared = $41.88, \mathrm{df}=1, \mathrm{P}<0.001$ ) with an average motility of fresh milt being $72.82 \pm 13.60 \%$, and that of cryopreserved milt $48.73 \pm 19.01 \%$. On average, milt samples treated with Mounib no GSH (tray height: $4.8 \mathrm{~cm}$ ) had the best motility recovery of all treatments, which was 27.4 pp higher than milt samples cryopreserved with Mounib plus EY (tray height $6.4 \mathrm{~cm}$ ), which had the

304 lowest motility recovery.

305

306 Tray height had a significant effect on post-thawing motility with the lower tray $(4.8 \mathrm{~cm})$

307 producing a $13.0 \mathrm{pp}$ higher motility than the higher one (Chi squared $=14.05, \mathrm{df}=1, \mathrm{P}<0.001$;

308 figure 1). Using different cryosolutions also affected the motility recovery; adding 'EY' to the

309 modified Mounib's medium resulted in a 19.3 pp lower motility while the modified Mounib's

310 medium had $6.4 \mathrm{pp}$ higher motility than the original Mounib's medium (Chi squared $=44.05$, $\mathrm{df}$

$311=2, \mathrm{P}<0.001$ ) (figure 1 ). 
313 The fertilisation success of eggs fertilised with fresh milt was not significantly higher than those 314 fertilised with cryopreserved milt $\left(30.81 \pm 16.87 \%\right.$ and $27.30 \pm 17.02 \%$ respectively; $F_{1,24}=$ $3150.91, \mathrm{P}=0.35$ ) (supplementary table 4).

316

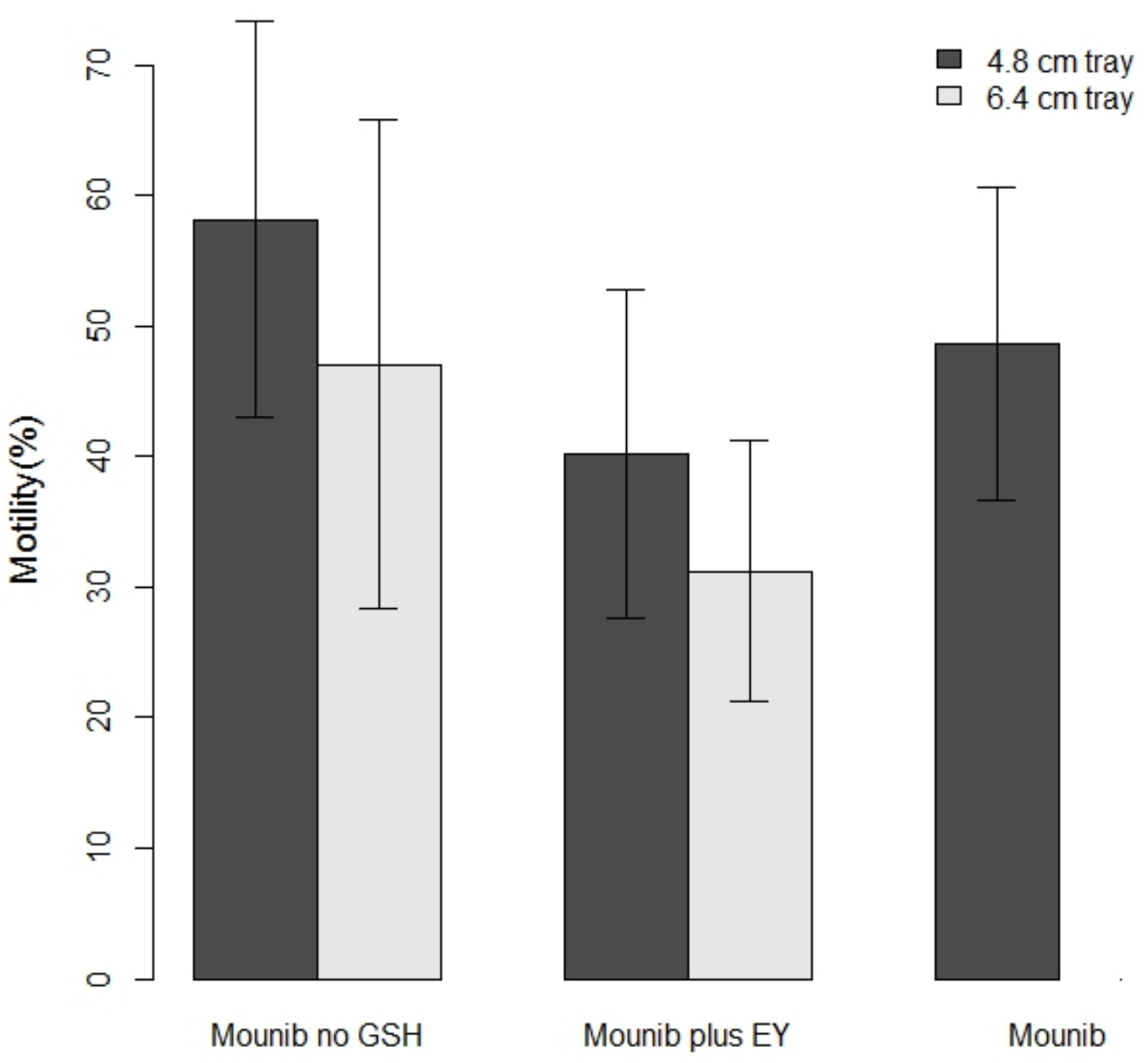

318 Figure 1. Mean motility of milt preserved in three different mediums on two different tray heights. Error bars 319 represent 1 standard deviation.

4. Discussion 
323 This paper details a successful method for cryopreserving lumpfish milt. To our knowledge no

324 such methodology has previously been published on this species, and this information may be

325 beneficial in future development of lumpfish as an aquaculture species. Our results indicate a

326 motility loss of less than $14.2 \mathrm{pp}$ when using our most optimal cryopreservation protocol. This is

327 comparable to cryopreservation of e.g. cod, halibut, ocean pout, sea bream, striped trumpeter and

328 turbot reviewed in Suquet et al. (2000), in which post-frozen motility recovery, expressed as a

329 percentage of fresh sperm motility rate, ranged from $39-85 \%$ compared to our result, which

330 was $80.92 \%$ at optimal tray height and cryosolution (67.8\% on average).

331

332 Based on previous findings in our pilot study, we tested three variants of Mounib's medium. Our

333 results indicate that the best diluent is Mounib's no GSH. This suggests that the penetrating

334 cryoprotectant DMSO is sufficient to protect the spermatozoa from cell damages that occur

335 during the freezing and thawing process. One would expect that the addition of GSH would have

336 a positive effect on motility recovery as it has been shown in other animal species that the

337 freezing process leads to a significant reduction of GSH content in spermatozoa (Bilodeau et al.,

338 2000; Gadea et al., 2004, 2005). In 2011, a study was carried out to test the antioxidant effect in

339 cryopreservation of fish spermatozoa by adding different antioxidants to cryosolutions including

340 GSH. The outcome was that the addition of GSH and any other antioxidant compound had no

341 significant effect on motility or fertility, and in some instances it had a slightly negative effect

342 (Lahnsteiner, Mansour \& Kunz, 2011). This is similar to our findings, but a more recent study

343 also using milt from rainbow trout (Oncorhynchus mykiss) revealed that addition of GSH (using

344 the same concentration as the study from 2011) to the cryosolutions actually did have an

345 significant positive effect on motility but no effect on fertility (Kutluyer et al., 2014). It is

346 possible that lumpfish milt benefits from the antioxidant property of GSH during a longer storage

347 period comparable to that in Mounib's study (1973).

348

349 Our pilot study indicated that a tray height of $2.5 \mathrm{~cm}$ was too low, and findings in this study

350 point to that 6.4 is too high with 13.04 pp lower motility than the lower tray $(4.8 \mathrm{~cm})$.

351 Interestingly, Rideout et al's $5.5 \mathrm{~cm}$ tray was better than their $3 \mathrm{~cm}$ tray. This suggests that there

352 may be an optimal tray height yet to be found or that optimal tray height is species dependent.

353 Perhaps the optimal height for lumpfish milt lies somewhere between 4.8 and $5.5 \mathrm{~cm}$. 
355 In Suquet et al. (2000) the optimal thawing temperature for marine fish species is said to vary 356 from $10-40^{\circ} \mathrm{C}$. We have only tested two thawing temperatures $\left(37^{\circ} \mathrm{C}\right.$ and $\left.50^{\circ} \mathrm{C}\right)$ in our pilot 357 study, which showed that $37^{\circ} \mathrm{C}$ is useful and $50{ }^{\circ} \mathrm{C}$ is not (supplementary table 2). The duration 358 time was $1 \mathrm{~min}$ or $1.5 \mathrm{~min}$ in that case, as samples were cryopreserved in vials, which need a 359 longer thawing period, compared with straws as they are thinner and have a larger surface area. 360 Therefore $37^{\circ} \mathrm{C}$ was used in this study and the thawing time (7 seconds) was estimated to end when bubbles appeared within the straw - indicating that samples were thawed. It could therefore be interesting to test if an even lower thawing temperature and using a longer thawing time would optimize the motility recovery of lumpfish milt. It is also possible that tray height and thawing temperature interact, in which case a tray height resulting in low motility recovery at one temperature may result in better recovery at a different temperature.

This study showed that cryopreserved lumpfish milt can be used to fertilise eggs. Using our cryopreservation method the fertilisation success was only $3.51 \mathrm{pp}$ lower using cryopreserved milt compared to fresh milt. The two groups were not significantly different, but our estimates are confounded by a number of factors that are not easily accounted for in this study. Female egg quality may differ drastically and thus fertilisation success (own observations), so variation seems to be large. Additionally, there are concerns regarding the ability to detect fertilised eggs early on (78-89 dd) as our own observations indicate a variability in speed of development. Because of this, some eggs that were in fact fertilised may have been classified as not fertilised. That being said, this kind of variation applies to both eggs fertilised with cryopreserved milt and fresh milt, so there was no systematic difference between the groups other than the milt used. In order to get good estimates of fertilisation success we recommend obtaining a much larger sample size from one single population of fish.

Establishing a captive lumpfish broodstock for a production of cleanerfishes with certain genetic qualities may become essential in the future. Being able to cryopreserve lumpfish milt is a necessary part of this process and we believe we have developed a reliable method, which can be put into use in most laboratories. It is also important to note, that cryopreservation of lumpfish milt according to this protocol can be achieved without use of expensive equipment. These 
385 findings and this protocol will contribute to a reliable year-round production of lumpfish

386 juveniles, and improve the utilization of the limited amounts of lumpfish milt available.

387 Ultimately, this could allow for the generation of more in-depth knowledge and use of this fish

388 species as a biological solution to sea-lice problems, without overfishing of the wild lumpfish

389 population.

390

391 In conclusion: cryopreservation of lumpfish milt prepared in modified Mounib's medium

392 (Mounib no GSH) in a 1:2 (milt:diluents) dilution along with 10\% DMSO is currently in use at

393 our own hatchery, using the lower freezing rate (trey height: $4,8 \mathrm{~cm}$ ) and thawing procedure: $37^{\circ}$

$394 \mathrm{C}$ for $7 \mathrm{sec}$. This study finds this to be the best combination of parameters, but the authors

395 acknowledge that the method may be even further improved upon in further studies.

396

397

398

399

400

401

402

403

404

405

406

407

408

409

410

411

412

413

414

\section{Acknowledgments}

Authors would like to thank the staff at Nesvík Marine Centre, Faroe Islands for their contribution in this study. As well as the staff at Føroya Sjósavn (The National Aquarium in Tórshavn, Faroe Islands) for helping with the capture of wild lumpfish males. Also we would like to thank Anne Laure Groison for helpful guidance, especially concerning some of the equipment used in this study.

\section{References}

Ashley PJ. 2007. Fish welfare: current issues in aquaculture. Applied Animal Behaviour Science 104:199-235.

Bates D, Maechler M, Bolker B, Walker S. 2014. lme4: Linear mixed-effects models using Eigen and S4. R package version 1.1-6. http://CRAN.R-project.org/package=lme4.

Billard R. 1992. Reproduction in rainbow trout: sex differentiation, dynamics of gametogenesis, biology and preservation of gametes. Aquaculture 100:263-298. 
Billard R, Cosson J, Crim LW, Suquet M. 1995. Sperm physiology and quality. In: in: N.R. Bromage, R.J. Roberts (Eds.) Broodstock management and egg and larval quality. Blackwell, Oxford. 25-52.

Bilodeau JF, Chatterjee S, Sirard MA, Gagnon C. 2000. Levels of antioxidant defenses are decreased in bovine spermatozoa after a cycle of freezing and thawing. Molecular reproduction and development 55:282-8.

Blaxter JHS. 1953. Sperm storage and cross-fertilization of spring and autumn spawning herring. nature 172:1189-1190.

Bolla, S., Holmefjord, I. Refstie, T., 1987. Cryogenetic preservation of Atlantic halibut sperm. Aquaculture, volume 65, pp. 371-374.

Clearwater SJ, Crim LW. 1995. Milt quality and quantity produced by yellowtail flounder (Pleuronectes ferrugineus) following GnRH-analogue treatment by microspheres or pellet. In: Austin, 113.

Costello MJ. 2009a. The global economic cost of sea lice to the salmonid farming industry. Journal of fish diseases 32:115-118.

Costello MJ. 2009b. How sea lice from salmon farms may cause wild salmonid declines in Europe and North America and be a threat to fishes elsewhere. Proceedings of the Royal Society B: Biological Sciences.

Davenport J. 1985. Synopsis of Biological Data on the Lumpsucker, Cyclopterus Lumpus (Linnaeus, 1758). FAO Fisheries Synopsis no.147, pp. 6-10.

Ding F, Lall SP, Li J, Lei J, Rommens M, Milley JE. 2011. Cryopreservation of sperm from Atlantic halibut (Hippoglossus hippoglossus, L.) for commercial application. Cryobiology.

Dreanno C, Suquet M, Quemener L, Cosson J, Fierville F, Normant Y, Billard R. 1997. Cryopreservation of turbot (Scophthalmus maximus) spermatozoa. Theriogenology 48:589603.

FAO. 2014. The State of World Fisheries and Aquaculture 2014. Rome: Food and Agriculture Organization of the United Nations.

Fauvel C, Suquet M, Dreanno C, Zonno V, Menu B. 1998. Cryopreservation of sea bass (Dicentrarchus labrax) spermatozoa in experimental and production simulating conditions. Aquatic Living Resources 11:387-394.

Fauvel C, Savoye O, Dreanno C, Cosson J, Suquet M. 1999. Characteristics of sperm of captive seabass in relation to its fertilization potential. Journal of fish biology 54:356-369. 
Fox J, Weisberg S. 2011. An \{R\} Companion to Applied Regression, Second Edition. Thousand Oaks CA: Sage.

Gadea J, Sellés E, Marco MA, Coy P, Matás C, Romar R, Ruiz S. 2004. Decrease in glutathione content in boar sperm after cryopreservation. Effect of the addition of reduced glutathione to the freezing and thawing extenders. Theriogenology 62:690-701.

Gadea J, Gumbao D, Matás C, Romar R. 2005. Supplementation of the thawing media with reduced glutathione improves function and the in vitro fertilizing ability of boar spermatozoa after cryopreservation. Journal of andrology 26:749-56.

Goulet D, Green J, Shears T. 1986. Courtship, spawning, and parental care behavior of the lumpfish, Cyclopterus lumpus L., in Newfoundland. Canadian journal of zoology.

Groison A-L, Suquet M, Cosson J, Mayer I, Severe A, Bouquet J-M, Geffen AJ, Utne-Palm AC, Kjesbu OS. 2010. Sperm motility in European hake, $<\mathrm{i}>$ Merluccius merluccius $</ \mathrm{i}>$, and characterization of its spermatozoa concentration and volume, spermatocrit, osmolality and pH. Aquaculture 301:31-36.

Gwo JC. 2000. Cryopreservation of sperm of some marine fishes. Cryopreservation in aquatic species 7.

Holst J. 1993. Observations on the distribution of lumpsucker ( Cyclopterus lumpus, L.) in the Norwegian Sea. Fisheries research.

Imsland AK, Reynolds P, Eliassen G, Hangstad TA, Foss A, Vikingstad E, Elvegård TA. 2014. The use of lumpfish (Cyclopterus lumpus L.) to control sea lice (Lepeophtheirus salmonis Krøyer) infestations in intensively farmed Atlantic salmon (Salmo salar L.). Aquaculture 424:18-23.

Jamieson BGM. 1991. Fish Evolution and Systematics: Evidence from Spermatozoa: with a Survey of Lophophorate, Echinoderm, and Protochordate Sperm and an Account of Gamete Cryopreservation. Cambridge University Press.

Johnson SC, Bravo S, Nagasawa K, Kabata Z, Hwang JS, Ho JS, Shih CT. 2004. A review of the impact of parasitic copepods on marine aquaculture. Zool. Stud. 43:229-243.

Kells VA, Carpenter K. 2011. A Field Guide to Coastal Fishes: From Maine to Texas.

Kennedy J, Jónsson S p, Kasper JM, Ólafsson HG. 2014. Movements of female lumpfish (Cyclopterus lumpus) around Iceland. ICES Journal of Marine Science: Journal du Conseil:fsu170.

Klokseth V, Øiestad V. 1999. Rognkjeks klargjøres for oppdrett. NFR 115897/120:1-26. 
Kutluyer F, Kayim M, Öğretmen F, Büyükleblebici S, Tuncer PB. 2014. Cryopreservation of rainbow trout Oncorhynchus mykiss spermatozoa: effects of extender supplemented with different antioxidants on sperm motility, velocity and fertility. Cryobiology 69:462-6.

Lahnsteiner F, Mansour N, Kunz FA. 2011. The effect of antioxidants on the quality of cryopreserved semen in two salmonid fish, the brook trout (Salvelinus fontinalis) and the rainbow trout (Oncorhynchus mykiss). Theriogenology 76:882-90.

Lanes CFC, Okamoto M, Cavalcanti P V, Collares T, Campos VF, Deschamps JC, Robaldo RB, Marins LF, Sampaio LA. 2008. Cryopreservation of Brazilian flounder (Paralichthys orbignyanus) sperm. Aquaculture 275:361-365.

Legendre M, Linhart O, Billard R. 1996. Spawning and management of gametes, fertilized eggs and embryos in Siluroidei. Aquatic Living Resources 9:59-80.

Lein I, Yoav B, Tveiten H. 2013. Sluttrapport - LeppeProd | FHF-Prosjektet. Production of Ballen Wrasse. Science and practice.

Mounib MS. 1978. Cryogenic preservation of fish and mammalian spermatozoa. Journal of Reproduction and Fertility 53:13-18.

Muus BJ. 1999. Freshwater fish. :180-181.

Ohta H, Izawa T. 1996. Diluent for cool storage of the Japanese eel (Anguilla japonica) spermatozoa. Aquaculture 142:107-118.

Quinn PJ. 1985. A lipid-phase separation model of low-temperature damage to biological membranes. Cryobiology 22:128-146.

Rasband WS. ImageJ.

Rideout RM, Trippel EA, Litvak MK. 2004. The development of haddock and Atlantic cod sperm cryopreservation techniques and the effect of sperm age on cryopreservation success. Journal of fish biology 65:299-311.

Schaer M, Vestvik NF. 2012. forberedelse og bruk av en lusespiser i laksemerd.

Skilbrei OT, Finstad B, Urdal K, Bakke G, Kroglund F, Strand R. 2013. Impact of early salmon louse, Lepeophtheirus salmonis, infestation and differences in survival and marine growth of sea-ranched Atlantic salmon, Salmo salar L., smolts 1997-2009. Journal of fish diseases 36:249-260.

Suquet M, Dreanno C, Fauvel C, Cosson J, Billard R. 2000. Cryopreservation of sperm in marine fish. Aquaculture Research 31:231-243. 
511 Tian YS, Chen SL, Ji XS, Zhai JM, Sun LJ, Chen C, Su PZ. 2008. Cryopreservation of spotted 512 halibut (Verasper variegatus) sperm. Aquaculture 284:268-271.

513 Torrissen O, Jones S, Asche F, Guttormsen A, Skilbrei OT, Nilsen F, Horsberg TE, Jackson D.

514 2013. Salmon lice - impact on wild salmonids and salmon aquaculture. Journal of fish 515 diseases 36:171-194.

516 Vinnumálaráðið. 1990. Løgtingslóg nr. 9 frá 14. mars 1985 um vernd av dýrum / værn af dyr, 517 sum seinast broytt við løgtingslóg nr. 60 frá 30. mai 1990. Available at:

518 http://logir.fo/Logtingslog/9-fra-14-03-1985-um-vernd-av-dyrum--vaern-af-dyr-sumseinast-broytt (accessed 26 March 2015)

Willumsen L. 2001. Fangst av rognkjeks (Cyclopterus Lumpus L.) og rognkjeks som lusespiser på laks. Gildeskål Forskningsstasjon a.s. GIFAS.

Wilson-Leedy JG, Ingermann RL. 2007. Development of a novel CASA system based on open source software for characterization of zebrafish sperm motility parameters. Theriogenology 67:661-672.

Young J. 1933. The preparation of isotonic solutions for use in experiments with fish. Pubbl. staz. zool. Napoli.

Zhang YZ, Zhang SC, Liu XZ, Xu YY, Wang CL, Sawant MS, Li J, Chen SL. 2003. Cryopreservation of flounder (Paralichthys olivaceus) sperm with a practical methodology. Theriogenology 60:989-996. 
Figure 1 (on next page)

Motility of cryopreserved sperm

Mean motility of milt preserved in three different mediums on two different tray heights.

Error bars represent 1 standard deviation. 


\section{Table $\mathbf{1}$ (on next page)}

Components included in cryopreserved samples

The chemical composition of the three cryosolutions tested in this experiment. All are based on Mounib's basic medium with and without reduced I-glutathione and hen's egg yolk. Mounib no GSH and Mounib plus EY were tested on two freezing trays (height 4.8 and 6.4 $\mathrm{cm}$ ), and Mounib was only tested on one tray (height $4.8 \mathrm{~cm}$ ). The concentration in every sample was: milt to diluent (1:2) and $10 \%$ of the diluent volume was DMSO. 
2

\begin{tabular}{l|l|l|l} 
Cryosolution: & Diluent: & Dilution: & Cryoprotectant \\
\hline Mounib & $\begin{array}{l}100 \mathrm{mM} \text { KHCO3, 125 mM Sucrose and } \\
6.5 \mathrm{mM} \text { L-Gluthatione (reduced) }\end{array}$ & $1: 2$ & $10 \%$ DMSO \\
\hline Mounib no GSH & $100 \mathrm{mM} \mathrm{KHCO3} \mathrm{and} \mathrm{125} \mathrm{mM} \mathrm{Sucrose}$ & $1: 2$ & $10 \% \mathrm{DMSO}$ \\
\hline Mounib plus EY & $\begin{array}{l}100 \mathrm{mM} \text { KHCO3, 125 mM Sucrose and } \\
10 \% \text { hen egg yolk }\end{array}$ & $1: 2$ & $10 \%$ DMSO \\
\hline
\end{tabular}

3 All reagents in this table are purchased from VWR, Bie \& Berntsen, Denmark.

4 